\title{
THE MEDIA STRATEGY FOR DESTINATION IMAGE BUILDING IN CRISIS
}

\author{
Binoy T. A.*
}

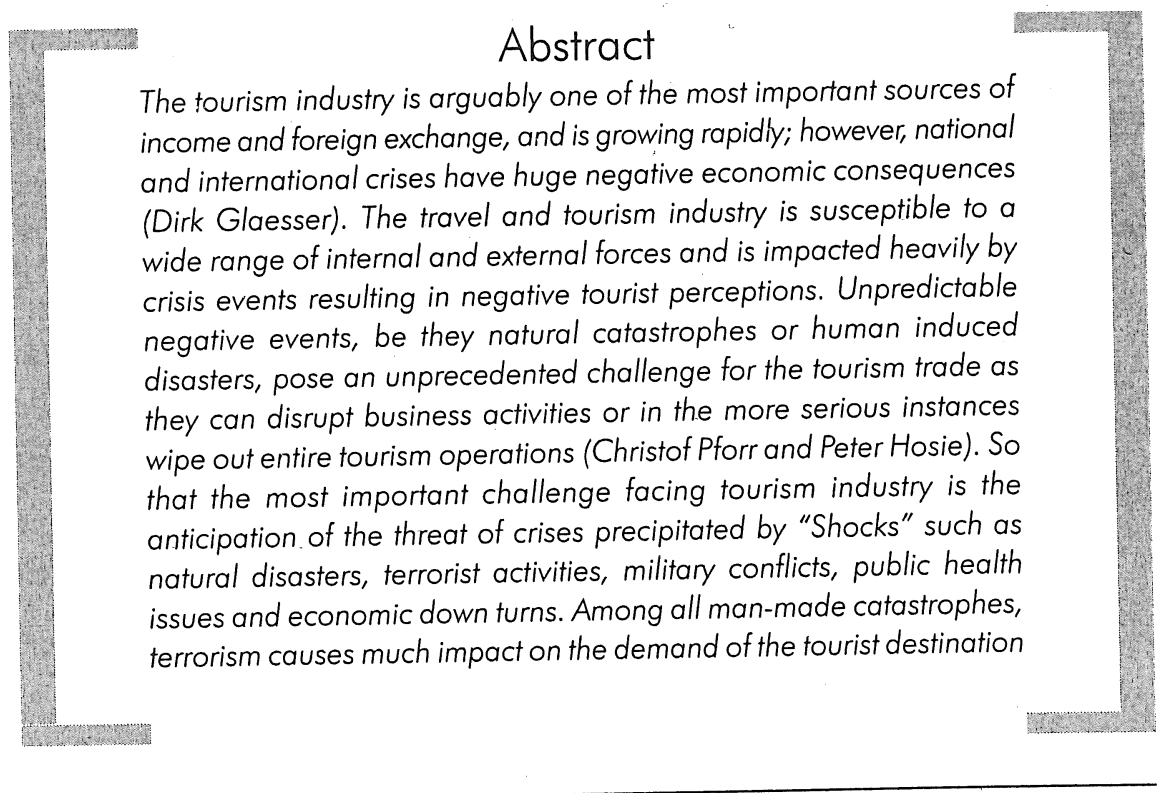

* Coordinator, Department of Tourism Administration, Kuvempu University, Shankaraghatta, Shimoga, Karnataka. 
and it destroys the image of the country. While tourists are free to avoid destinations associated with risk, the consequences of disastrous events on tourist destinations are inescapable and can be profound. Terrorism that targets tourism can be viewed as a disaster for a destination and ensuing events can create a serious tourism crisis (Sevil F. Sönmez, 1999). There is a need for a systematic and conceptual approach to questions such as how tourism businesses prepare for and react to crisis, which measures are taken and what impact they have, and which strategies can be employed to overcome them. Crisis Management in the Tourism Industry means to formulate adequate theories and actions that can be taken to better understand consumer, economic and environmental reaction, in order for the businesses involved to be more prepared for such events. Tourist destinations of such countries, especially those vulnerable to politically motivated violence, should incorporate crisis management planning into their overall sustainable developmentand marketing management strategies to protect and rebuild theirimage of safety and attractiveness, to reassure potential visitors of the safety of the area, to reestablish the area's functionality and attractiveness, and to aid local travel and tourism industry members in their economic recovery. The concerned authorities should design a crisis managementplan in place, establishing a tourism crisis management task force, developing a crisis management guidebook, and partnering with law enforcement officials. The growing competition between countries and cities over attracting tourism investments and tourists, today, international tourism demand is concerned; a negative image of a destination is more harmful than ever (Avraham and Ketter, 2008). This research paper tries to discuss various dimensions of image crises and different strategies to overcome it based on secondary data. This paper has been prepared with a notion that the image of a tourist destination deeply influences the consumer buying behavior and media can play a central role in destination image building process. The media management and marketing strategies during crisis are very pivotal for every effective tourism crisis management and it should be a part of the overall crisis management plan. Media plays a vital role in rebuilding the image of a destination and a proactive media plan is required to tackle the array of problems due to crisis. In the age of WWW, Satellites, Global TV networks etc have the capability to empty out hotels, cancel flights and reservations and leave tourist destinations deserted overnight. The research paper is also trying to answer for the question that how does media can be better used for image management of a destination in crises. 


\section{Introduction}

Tourism is highly vulnerable to economic uncertainty and volatility for a simple reason. Most travel and tourism involves discretionary expense. During tough economic times people conserve their cash to cover the essentials of life, food, shelter and family necessities (David Beirman, 2008). The new millennium has witnessed by several global crises since the terrorist attacks in New York City and Washington D.C. on September 1 1, 2001. There have been several terrorist inflicted tourism crises from the Bali bombings on October 12, 2002 to the most recent hotel bombings in Amman Jordan in November 2005 and the terrorist attack at hotel Taj Mahal and Oberoi Trident, Mumbai in November 2008. In addition to these crises, tourism has suffered from serious health crises including the foot and mouth disease 2001, the SARS epidemic in 2003 and the bird flu that started to expand in June 2002 and threatens to become a global pandemic. Tourism has also been impacted by several natural disasters including earthquakes, flooding, wild fires, hurricanes (i.e. Katrina and Rita in New Orleans and Texas, October 2005, and Wilma in Mexico, November 2005), and the most devastating Tsunami in December 2004 (Manisha Shekhar, 2009).

The term, Crisis management has a recent origin, emerged as a new management concept during the mid-nineteenth century and the term is now widely used in all walks of human life. Business Administration predominantly terms crises as a process that negatively influences the development of a company to a considerable extent (Krystek, 1987; Schulten, 1995). So that Crises Management is the process through which the negative influences are tackled to minimize the impacts of these negative forces particularly to the company and in general to the nation. The tourism industry is arguably one of the most important sources of income and foreign exchange, and is growing rapidly; however, national and international crises have huge negative economic consequences (Dirk Glaesser). Tourism Crises Management is very much imperative for those countries in which their economy is largely based on tourism industry like Mauritius, Spain, Caribbean Islands etc and those countries have being affected by either natural catastrophes or human induced disasters. A sustained drop-off in tourism due to any sort of natural or manmade reasons will translate into a serious economic downturn and threaten the fiscal, social and political stability of countries in some of the world's major emerging tourism markets such as Egypt and Indonesia. The term Crises in tourism industry could be understood by a situation in which a tourism destination is confronted with sudden, unpredictable, catastrophic changes over which it has little control' (Faulkner \& Russell 2000). Living in the ever-changing world of the 21 st century, crises have become a familiar problem for a growing list of countries, regions and cities. Popular tourist destinations such as New York, London and Madrid have suffered from terror attacks; the killer 
tsunami of 2004 swept the beaches of Thailand, India and Sri Lanka; epidemics of SARS, foot-and-mouth disease and other illnesses had a severe affect on tourism in the UK, China and Canada; and Hurricane Katrina destroyed one of the US's fabled tourist destinations in 2005.

In the age of the World Wide Web, satellites, global TV networks and the global economy, crises such as these are widely covered in the international media and can empty out hotels, cancel flights and leave tourist attractions deserted overnight. On the other hand, in contrast to sudden unexpected crises, countries such as those of Africa, the former communist countries of Eastern Europe, Middle Eastern countries, as well as cities and regions in more developed countries, can gradually develop negative images as the cumulative result of a problematic past, peripheral location, neglected tourism infrastructure, high crime rates and social problems. In both scenarios-the sudden downturn in image resulting from a particular crisis and the development of a gradual negative image-an unfavorable image is projected in the media and has a correspondingly negative effect on the national and international tourism industry and on the place's economics, investments, commerce and its attractiveness to current and potential residents (Avraham and Ketter, 2008).

The growing competition between countries and cities over attracting infrastructure, investment, tourists, capital and national and international status mean that today, a negative image is more harmful than ever. Whatever the cause of the negative image, places perceived as dangerous, frightening, or boring are at a distinct disadvantage. Many decision makers and marketers stand by helplessly, frustrated by their knowledge that in most cases, their city's negative image is not based on well-grounded facts. Given that stereotypes are not easily changed or dismissed, the challenge facing these decision makers is great. Analyses of many case studies show interesting examples of places that tried to change a negative image into a positive one, in order to bringing back tourists, investors and residents.

\section{What is Crises?}

A crisis is an undesired, extraordinary, often unexpected or timely limited process with ambivalent development possibilities. It needs immediate decisions and counter measures in order to influence the further development again positively for the organization/destination and to limit the negative consequences as much as possible. Crises situation is determined by evaluating the seriousness of the occurring negative events, which threaten, weaken or destroy complete advantages or important goals of the organization/destination (Glaesser, 2006). 


\section{Types of Crisis}

- Crime-related events such as robbery, rape, murder or kidnapping

- Terror-related events such as bombing of public places, plane hijackings

- Political Unrest - events such as violent demonstrations, uprising or riots

- Natural disasters - events such as earthquakes, forest fire, extreme heat/cold/ waves/hurricanes/tsunami/land slides etc

- Epidemics-related events such as SARS, AIDS, or foot and mouth diseases

\section{Crises Management in tourism}

Crises management in tourism is the strategies, processes and measures which are planned and put in to force to prevent and cope with crisis (Glaesser, 2006)

\section{Crises communication management}

The media are well known for their preferences for negative news, from the early days of journalism, it was clear to the editors that stories covering sensations, human sufferings, violence and crime were the best way to sell the news papers. Crisis communication is the communication between the organization and its public prior to, during, and after the negative occurrence (Fearn Banks, 1996). Crisis communication is an ongoing process in which the places or the organization is consistently communicating with the public.

\section{Crisis communication techniques}

One of the major aspect of crisis communication management is the techniques, a set of practical procedures applied to control the story at any given time. The four basic principles of crisis communication are,

- $\quad$ Respond quickly - Develop two-way communication with the media to reduce misinformation and help get the message through

- Speak with one voice

- Openness

- Express sympathy to the victims 


\section{The Concept of Place or Destination Marketing}

The conceptual foundation of place marketing lies in marketing theories; primarily the marketing mix approach (Olsson and Bergland, 2006). Marketing mix is an effective combination of various marketing components like product, place, promotion, price, process, physical evidence and people. Place promotion involves the revaluation and re representation of place to create and market a new image of localities to enhance their competitive position in attracting or retaining resources. Place promotion is defined as the conscious use of publicity and marketing to communicate selective images of specific geographical localities or areas to a target audience (Gold and Ward, 1994). Correctly speaking, place marketing is a social public marketing activity since the 'place' usually belongs to the government or public. Therefore the public relation is one among crucial and pivotal components of destination or place marketing process such as motivating the journalists to write favorable news and columns. The main methods for assessing the campaign efficiency is to device and run a pre and post campaign survey for evaluating the effect on the target audience's approach to the place and evaluating the change in the actual place consumption.

\section{A place's public image}

Most important challenge and task of tourism marketer is to create a good about image the destination or place in the minds of the potential travelers and the public. The image of a place is the sum beliefs, ideas and impressions people have towards a destination (Kotler et al 1993). Place image is also defined as the sum of cognitive, affective, evaluative and behavioral characteristics of a place or inherent perspective of itself (Elizur, 1987).

- Cognitive (what one knows about a place)

- Affective (how one feels about a certain place)

- Evaluative (how one evaluates the place or its residents)

- Behavioural (whether one's willingness to visit a place)

\section{Strategic Image Management (SIM)}

One of the recently developed concepts of place marketing is strategic image management (SIM). This is a continuous process of researching a place's image among the target populations, clarifying its advantages, examining the factors 
influencing its image and making changes over the years, handling image related crises and delivering relevant messages to different audience. The main advantage of this strategy is that the involvement of many different bodies in the marketing campaign requires co ordination in planning, implementing and following the marketing programme.

\section{Marketing Campaign Examples}

- The Ministry of Tourism as apart of the $60^{\text {th }}$ Anniversary of Indian Independence, had launched a campaign called, 'Sare Jahan se Achcha' and displayed through various media and Cinema Halls

- From Spain to "Espana"

- "Malaysia, Truly Asia"

- Made in NY, I Love New York, The World's Second Home

- $4^{\text {th }}$ phase of Athithi Devo Bhava Campaign through TV, Cinema, FM Radio, News papers etc

- Amir Khan has been appointed as the brand ambassador for Athithi Devo Bhava.

- Incredible India campaign launched by Ministry of Tourism

- Life in a different light (Australia)

- Poland, I am awaiting you

- Esthonia-Positively Transforming

- There is more to Japan than Business

\section{Place Positioning and Branding}

Place promotion is described as the active shaping of the place image in relation to competing places (Short and Kim, 1993). Place branding has become one of the most popular concepts in the field of marketing places in general and tourist destinations in particular. In recent years, place positioning has merged with the concept of place branding. A brand is a symbol (Logo, color, shape, package, design etc), an object, a concept or a combination of them, aimed at identifying goods or services and distinguishing them from their competitors (Herstein 2000). 
During crises, the rejuvenation of a place or a destination is purely depends on the place positioning and branding strategies adopted by the concerned parties.

\section{Tackling the crisis}

Some of the methods for tackling the crisis are mentioned below

- Hosting Spotlight events

i. Hosting Olympic Games

ii. Hosting spots events

iii. Hosting Cultural events

- Hosting opinion leaders

- Hosting conventions and conferences

- $\quad$ Promoting places using films, television series and books

- Using film to promote places

- Using works of fiction to promote places

- Hosting celebrities

i. Celebrities are opinion leaders and indicators of excellence

ii. Celebrities as brand ambassadors

iii. Celebrities as means to attract public attention

- Delivering a counter message

- $\quad$ Spinning liabilities to assets

- Spinning a controversial heritage in to an asset

- Spinning geographical location in to asset

- Spinning natural and historic disasters into assets

- Changing the places name 


\section{Tourism Crises Management and Role Strategy of Media}

Whenever we discuss the role of media in crises management, it is concerned with an important aspect, that is, the role of public relations and advertising strategies in the efforts to lessen the image damage in affected tourism destinations by the concerned stakeholders of tourism of the country or region and in vice versa it can also be said that the negative image that emerges in the wake of security incidents is a result of two major forces operating simultaneously: the media and the governmental travel advisories.

Based on the above mentioned assumptions the following suggestions are concluded:

- There is a direct relation between the image of the affected tourist destination and the level of demand generated by tourists to visit it.

- A proper strategic planning is needed in order to develop an effective image management strategy. Considerable attention in planning long-term image management campaigns should be devoted to the deflecting of potential crises since such an approach has proved to be highly efficient.

- Media campaigns cannot be utilized on a stand-alone basis when dealing with security induced tourism crises. They have to be part of a comprehensive and concerted effort operating in different yet complementary channels.

- Media campaigns must be accompanied by overall improvement of the tourist product, including the level of security provided to safeguard the life of tourists and the quality of their tourist experience.

- When concerted and well-coordinated efforts took place, involving international organizations, as well as regional-national bodies and national tourism organizations in the 2002-2003 tourism crises, they proved to yield a fast and effective recovery process.

- Contingency marketing plans can shorten the time lag between tourism crisis situations and actual recovery trends.

- Private-public cooperation with strong governmental commitment to tourism is vital for successful and rapid recovery from security oriented tourism crises. One of the factors that shape tourists' risk perception, and thus their subsequent travel behavior, is the availability of security oriented information and the type of information source. 
- It is implicit that the importance of crisis communications and of generating balanced, comprehensive, and up-to-date security information, to control the security image of potential and actual tourists.

- The proactive provision of security and risk related information by the host destinations is imperative in order to balance the biased information provided by the media and governments in the generating markets.

- The provision of comprehensive and accurate security related information should not target would-be travelers but be directed toward those who have already made a commitment to travel to affected destinations; tourists who are visiting affected destinations; and tourists who have already returned from a visit to affected destinations.

- Information on current security situations in affected destinations should not be based only on facts, but also on their interpretation in order to assist tourists to make a more balanced evaluation of the risk involved.

- The provision of security information by affected destinations should be both proactive and dynamic to increase the confidence of tourists in this type of information source.

\section{What should be the strategy for managing the Mumbai Type Terrorist Attack?}

Mumbai, November 27, 2008, the top floor of the world-famous Hotel Taj Intercontinental in Mumbai caught fire after a bomb explosion as terrorists struck at seven locations in the metropolis late Wednesday night! The blood-chilling news shocked the Indian Tourism industry across entire world! What should be the strategy to tackle this?

Let us see the crises management strategy followed by USA after September 11 , World Trade Centre attack.

Larry Yu and Alex Kobina Armoo evaluate the success story of Washington, DC, hotels responded to the September 11, 2001, terrorist attack on the Pentagon. Following an in-depth analysis of the human and financial implications of this crisis on the local hospitality sector,

- A well-coordinated effort from the early stages of the tourism crisis, accompanied by proper objectives, helped hospitality businesses in the Washington, DC, area regain their pre-September 11 business levels. 
- This success was attributed to the well-coordinated and centralized industry response which provided a single and reliable information source about the industry status.

- The lesson as to how the DC hospitality sector dealt with the crisis is that contingency plans must be built on solid knowledge of crisis-management skills and refined through workplace practices.

- When emergency conditions have subsided, management must make the transition quickly to the process of recovery.

- Familiarity with crisis characteristics will better enable hotel managers to handle future security oriented crises. On a similar topic but more related to crisismanagement strategies among hotel managers,

Aviad Israeli and Arie Reichel discuss how the Israeli hospitality sector tried to mitigate the ramifications of the second period of Palestinian uprising (the Intifada). Their main conclusions are that:

- When assessing the performance of hotel managers in times of security induced tourism crises, there is a need to examine both their recognition of the importance of measures that assist the organization in times of crisis and also their level of usage.

- Four crisis management practices were identified among Israeli hotel managers: marketing, infrastructure (or hotel) maintenance, human resources, and governmental assistance.

- With regard to hotel managers in the Israeli hospitality sector, there is considerable correspondence between their perceived practices, importance and their usage. And lastly

\section{Tips for an effective media management during crises}

- Plan for a crisis in advance

- Clarify your communication objectives

- Determining the spokes person and test their skills prior to crises

- Identify the best channels of Communication

- What is the key message?

- Stick to the facts and be empathy with the affected 
- Develop an open and honest relationship with media

- Seek professional Help

\section{Conclusions}

Disasters create difficult, often tragic, situations for the afflicted area and its residents. For a tourist destination, this period can represent a tourism crisis, which can threaten the normal operation and conduct of tourism-related businesses; damage a tourist destination's overall reputation for safety, attractiveness, and comfort by negatively affecting visitors' perceptions of that destination; and, in turn, cause a downturn in the local travel and tourism economy, and interrupt the continuity of business operations for the local travel and tourism industry, by the reduction in tourist arrivals and expenditures. Prudent and timely implementation of effective crisis management strategies helps every crisis affected destinations to come up with better performance and it can be proactive towards the negative occurrences. Media plays a vital role in rebuilding the image of a destination and encourages more people to visit the destination. The concept of Black Tourism, visiting crisis affected destinations, is a newly emerged tourism concept that can bring more tourists to the destinations which are affected by crises.

\section{References}

Dirk Glaesse (2006), Crisis Management in the Tourism Industry, Butterworth-Heinemann, 2nd edition.

Eli Avraham and Eran Ketter, Media Strategies for Marketing Places in Crises-Improving the mage of Cities, Countries and Tourist Destinations, Butterworth-Heinemann, 2008.

Paradise Lost? Report: Hawaii's tourism industry in 'crisis mode' by AP, April 02, 2009.

Some cause for industry hope in new PATA Tourism Forecasts, TN Staff Writer, April 02, 2009.

David Beirman, Travel News, Oct 15, 2008, Tourism and the Global Economic Crisis of 2008.

Vicky Karantzavelou - Friday, March 27, 2009, Dubai tourism defies global financial crisis.

Theodore Koumelis, Greece: Crisis ripples through Greece's tourism, Travel Daily News, Thursday, April 02, 2009.

Some cause for industry hope in new PATA Tourism Forecasts, eTN Staff Writer, April 02, 2009.

Factors Influencing Crisis Management in Tourism Destinations, K Campiranon and N Scott, The University of Queensland, Australia.

Crisis Communication Response Strategies: A Case Study of the Irish Tourist Boards Response to the 2001 European Foot and Mouth Scare, S Tiernan, University of Limerick, Ireland. 
Sevil F. Sönmez, Tourism in Crisis: Managing the Effects of Terrorism, Journal of Travel Research, Vol. 38, No. 1, 13-18 (1999).

Barbara A Anderson, Crisis management in the Australian tourism industry: Preparedness, personnel and postscript, Tourism Management, Volume 27, Issue 6, December 2006, Pages 1290-1297.

Olsson, K and Bergland E. (2006), Challenges using culture as a resource in city marketing practice.

Manisha Shekhar, Tourism Crisis Management Framework: Case Study on the Thai Experience, The Seoul Times, Tuesday, April 28, 2009. 